\title{
Low serum vitamin D levels are not associated with increased postoperative pain and opioid requirements: a historical cohort study
}

\section{Des taux faibles de vitamine $D$ sérique ne sont pas associés à une augmentation de la douleur postopératoire et des besoins en opioïdes: une étude de cohorte historique}

\author{
Somnath Bose, MD • Ashish Khanna, MD · Jing You, MS • Lovkesh Arora, MD • \\ Shahbaz Qavi, MD • Alparslan Turan, MD
}

Received: 5 August 2014/ Accepted: 25 February 2015/Published online: 10 March 2015

(C) Canadian Anesthesiologists' Society 2015

\begin{abstract}
Purpose Vitamin D deficiency has been associated with chronic non-specific musculoskeletal pain syndromes; however, studies are lacking with respect to its relationship with postoperative pain. We tested the hypothesis that a lower preoperative vitamin D level is associated with increased postoperative pain and/or opioid consumption in morbidly obese patients who had laparoscopic bariatric surgery.
\end{abstract}

Methods Data from 185 patients who underwent laparoscopic bariatric surgery at the Cleveland Clinic from 2005-2009 and had a vitamin D level checked within

Presented at the October 2013 American Society of Anesthesiologists' Annual Meeting, San Francisco, CA.

Author contributions Somnath Bose, Alparslan Turan, Jing You, Lovkesh Arora, and Shahbaz contributed to the study design. Somnath Bose, Alparslan Turan, Ashish Khanna, Lovkesh Arora, and Shahbaz Qavi contributed to the conduct of the study. Jing You, Lovkesh Arora, and Shahbaz Qavi contributed to data analysis. Somnath Bose, Alparslan Turan, Ashish Khanna, Jing You, Lovkesh Arora, and Shahbaz Qavi contributed to manuscript preparation.

S. Bose, MD · A. Khanna, MD · L. Arora, MD · S. Qavi, MD

Anesthesiology Institute, Cleveland Clinic, Cleveland, OH, USA

J. You, MS

Departments of Quantitative Health Sciences and Outcomes

Research, Cleveland Clinic, Cleveland, OH, USA

A. Turan, MD ( $\square)$

Department of Outcomes Research, Cleveland Clinic, 9500

Euclid Avenue, P-77, Cleveland, OH 44195, USA

e-mail: turana@ccf.org

URL: http://www.OR.org three months of their surgery were included in the analysis. We assessed the relationship between vitamin D levels and the time-weighted average (TWA) of pain scores and total opioid consumption using multivariable regression models adjusted for potential confounders. As a secondary analysis, we compared the TWA of pain scores and opioid consumption between patients who were vitamin $D$ deficient $\left(\leq 20 \mathrm{ng} \cdot \mathrm{mL}^{-1}\right)$ and those who were not (vitamin $\left.D>20 n g \cdot m L^{-1}\right)$.

Results The mean (SD) TWA pain score was 3.8 (1.5) and the median interquartile range [IQR] total opioid consumption (morphine equivalent) was 15.6 [18.2] mg during the first $72 \mathrm{hr}$ postoperatively. The median [IQR] vitamin $D$ concentration was 21.8 [17.1] $n g \cdot m L^{-1}$. The vitamin D level was not significantly associated with either the TWA pain score (Pearson correlation: -0.003; $97.5 \%$ confidence interval [CI]: -0.17 to 0.16) or opioid consumption (Spearman correlation: -0.13; 97.5\% CI: -0.30 to 0.03). After adjusting for confounders, the estimated average change in TWA pain score was 0.01 (97.5\% CI: -0.08 to 0.11) for a five-unit increase in vitamin $D(P=0.77)$. The estimated ratio of geometric means of total opioid consumption was 0.94 (97.5\% CI: 0.86 to 1.03$)$ for a five-unit increase in vitamin $D$ concentration $(P=0.12)$. No difference was found between patients with vitamin $D$ concentrations $>20$ $n g \cdot m L^{-1}$ and $\leq 20 \mathrm{ng} \cdot \mathrm{mL}^{-1}$ in either TWA pain score $(P=0.91)$ or total opioid consumption $(P=0.18)$.

Conclusion We did not find any association between preoperative vitamin $D$ levels and postoperative pain scores/opioid consumption in morbidly obese patients undergoing bariatric surgery. 


\section{Résumé}

Objectif Un déficit en vitamine $D$ a été associé à des syndromes chroniques de douleurs non spécifiques de l'appareil locomoteur; nous manquons toutefois d'études pour ce qui concerne ses rapports avec la douleur postopératoire. Nous avons testé l'hypothèse que des taux plus faibles de vitamine D préopératoire étaient associés à une augmentation de la douleur postopératoire et/ou de la consommation d'opioüdes chez les patients ayant une obésité morbide et subissant une chirurgie bariatrique laparoscopique.

Méthodes Les données de 185 patients ayant subi une chirurgie bariatrique laparoscopique à la clinique de Cleveland, entre 2005 et 2009, et dont les taux de vitamine $D$ avaient été dosés dans les 3 mois précédant la chirurgie, ont été incluses dans l'analyse. Nous avons évalué les rapports entre les taux de vitamine $D$ et la moyenne pondérée en fonction du temps (TWA) des scores de douleur et de la consommation totale d'opiö̈des en utilisant des modèles de régression multifactorielle ajustés pour d'éventuels facteurs confondants. L'analyse secondaire a comparé la TWA des scores de douleur et de consommation d'opiö̈des entre les patients qui avaient un déficit en vitamine $D\left(\leq 20 \mathrm{ng} \cdot \mathrm{mL}^{-1}\right)$ et ceux qui n'en avaient pas (vitamine $D>20 \mathrm{ng} \cdot \mathrm{mL}^{-1}$ ).

Résultats Le score moyen (ET) de TWA de la douleur était de 3,8 (1,5) et l'intervalle interquartile médian (IQR) de la consommation totale d'opioüdes (morphine équivalent) était de 15,6 (18,2) mg au cours des 72 premières heures postopératoires. La concentration médiane (IQR) de vitamine $D$ était de 21,8 (17,1) $n g m L^{-1}$. Le taux de vitamine $D$ n'a pas été associé de manière significative avec la TWA de score de douleur (corrélation de Pearson:-0,003; intervalle de confiance [IC] à 97,5\%: -0,17 à 0,16) ou la consommation d'opioüdes (corrélation de Spearman: -0,13; IC à 97,5 \%: -0,30 à 0,03). Après ajustement pour les facteurs confondants, la variation moyenne estimée du score de TWA de douleur était de 0,01 (IC à 97,5\%:-0,08 à 0,11) pour une augmentation de 5 unités de vitamine $D(P=0,77)$. Le rapport estimé des moyennes géométriques de la consommation d'opiö̈des totale était de 0,94 (IC à 97,5\%: 0,86 à 1,03) pour une augmentation de 5 unités de la concentration en vitamine $D(P=0,12)$. Aucune différence $n$ 'a été constatée entre les patients ayant des concentrations de vitamine $D>20 \mathrm{ng} \cdot \mathrm{mL}^{-1}$ et $\leq 20 \mathrm{ng} \cdot \mathrm{mL}^{-1}$ pour les scores de douleur moyenne pondérée en fonction du temps $(P=0,91)$ ou pour la consommation totale d'opioüdes $(P=0,18)$.

Conclusion Nous n'avons pas trouvé d'association quelconque entre les taux préopératoires de vitamine $D$ et les scores de douleur/consommation d'opiö̈des postopératoires chez des patients ayant une obésité morbide et subissant une chirurgie bariatrique.
Vitamin D deficiency is a common public health problem. In the United States alone, about 25 million people are deficient in vitamin $\mathrm{D} .{ }^{1}$ On a global scale, this translates into nearly 100 million people worldwide who have vitamin D deficiency or insufficiency. ${ }^{2}$ The prevalence of vitamin D deficiency in morbidly obese patients presenting for bariatric surgery is estimated to be as high as $60 \% .^{3}$ This has been attributed to an increase in sequestration of vitamin $\mathrm{D}$ in adipose tissues, ${ }^{4}$ secondary hyperparathyroidism, ${ }^{5}$ and avoidance of sunlight with a tendency towards wearing protective clothing. ${ }^{6}$ Additionally, this deficiency state is exacerbated after bariatric surgery. ${ }^{7-9}$

Vitamin $\mathrm{D}$ has been linked with important anti-inflammatory and immunomodulatory roles where it regulates cytokines and profibrotic and pro-inflammatory pathways that play an important role in pain perception and propagation. ${ }^{10-15}$ Clinically, vitamin D deficiency has been associated with chronic non-specific musculoskeletal pain syndromes and migraines. ${ }^{16-18}$ Vitamin $\mathrm{D}$ deficient individuals have reported pain even in the absence of actual bone pathology. ${ }^{19}$ A Cochrane review highlighted an association between pain, geographic latitude and sun exposure, which may be an indirect pointer to the role of hypovitaminosis $\mathrm{D}$ and its role in pain. ${ }^{20}$ In patients with advanced malignancies, vitamin D deficiency has been related to pain, fatigue, and muscle weakness. ${ }^{21}$ Furthermore, replacement therapy has been reported to improve bone pain and muscle strength in patients with prostate cancer. ${ }^{21,22}$ A recent case series reported treatment with vitamin $\mathrm{D}$ in the palliative medicine clinic where patients with chronic cancer pain refractory to conventional therapy showed a favourable response. ${ }^{23}$

Surgical incision releases inflammatory mediators that reduce the pain threshold at the injury site and in the surrounding uninjured tissue. The combination of vitamin $\mathrm{D}$ deficiency and surgical incision may thus be especially deleterious. Nevertheless, previous studies are lacking on the relationship between preoperative vitamin D levels and postoperative pain. Thus, we tested the primary hypothesis that lower perioperative vitamin D concentrations are associated with increased postoperative pain and/or opioid consumption in the immediate postoperative $(72 \mathrm{hr})$ period.

\section{Methods}

With Cleveland Clinic Institutional Review Board approval (IRB\# 11-462, approval 5/2011), written informed consent was waived for this retrospective cohort analysis. The investigation included 210 adult patients who had laparoscopic bariatric surgery and serum vitamin D concentration measured at the Cleveland Clinic Main 
Campus during July 6, 2005 to December 30, 2009. The Cleveland Clinic Perioperative Health Documentation System and paper charts were used to recover patient information, including age, sex, race, and body mass index, smoking status, and comorbidities (e.g., diabetes mellitus, chronic pain disorder, and chronic use of steroids and/or opioids). The analysis also included the available pain scores (11-point numerical rating scale: $0-10 ; 0=$ "no pain at all" and $10=$ "worst pain imaginable") collected in the postanesthesia care unit (PACU) (every $15 \mathrm{~min}$ ) and surgical wards (every four hours), according to standard practice, as well as the doses of analgesic medications the patients received in these settings during the first $72 \mathrm{hr}$ after surgery.

All patients who had a 25-hydroxyvitamin D measurement within three months from the date of surgery were considered for inclusion. Since the prevalence of vitamin $\mathrm{D}$ deficiency is significant in this cohort, the decision to order vitamin D levels was left to the discretion of the clinicians who assessed the patients initially. We also used techniques to quantify potential selection bias arising out of clinician discretion (detailed in statistical section). A single vitamin D concentration value was used for the analysis, and if multiple measurements were obtained within the above time frame, the value measured closest to the date of surgery was used. Vitamin D concentrations were obtained from the hospital Laboratory Medicine registry. We excluded patients with missing outcomes and/or covariables.

\section{Postoperative pain management}

According to standard practice in the Cleveland Clinic, patients are evaluated by the nursing staff upon their arrival in the PACU, and if required, analgesic medications are administered according to anesthesiologists' orders. Current standard opioids administered for postoperative pain management in the PACU are fentanyl, morphine, and/or hydromorphone. Patients are given incremental doses of the prescribed opioids to keep pain scores (numerical rating scale) below 4, and vital signs are monitored: electrocardiography, heart rate, noninvasive blood pressure, and pulse oximetry. In the postoperative ward, patients receive intravenous opioids by either patientcontrolled analgesia or incremental doses of opioids until they can tolerate oral medications, per the standards of the surgical team. Data were collected from medical records, and the total amount of opioids used in $72 \mathrm{hr}$ was converted to a morphine equivalent for analysis (Table 1).

Statistical analysis

Patient characteristics and outcomes were summarized using the standard summary statistics, as appropriate. To
Table 1 Demographics and baseline characteristics $(n=185 *)$

\begin{tabular}{lc}
\hline Variable & Statistics $^{\dagger}$ \\
\hline Age (yr) & $48(12)$ \\
Sex (female), $n(\%)$ & $133(72)$ \\
Race, $n(\%)$ & \\
Caucasian & $149(81)$ \\
African American & $23(12)$ \\
Others & $13(7)$ \\
Body mass index (kg.m $\left.{ }^{-2}\right)$ & $45(9)$ \\
Smoking status (smokers), $n(\%)$ & $89(48)$ \\
Diabetes, $n(\%)$ & $75(41)$ \\
Chronic steroid users, $n(\%)$ & $7(4)$ \\
Chronic opioid users, $n(\%)$ & $54(29)$ \\
Chronic pain syndrome, $n(\%)$ & $56(30)$ \\
\hline
\end{tabular}

*Of 476 patients who underwent laparoscopic bariatric surgery at Cleveland Clinic Main Campus (2005-2009), 210 patients had at least one 25-hydroxyvitamin D measurement within six months from the date of surgery. Twenty-five patients with missing outcomes and /or other covariates were excluded from the analysis

${ }^{\dagger}$ Statistics are represented as mean (SD) or $n(\%)$

investigate the potential selection bias, we compared patients included in the study with those excluded using the absolute standardized difference (ASD), that is, the absolute difference in means or proportions divided by the pooled standard deviation. Values of $0.2,0.5$, and 0.8 represent small, medium, and large differences, respectively. ${ }^{24}$

We assessed the relationships between vitamin D concentration and the time-weighted average (TWA) of pain scores and total opioid consumption in the first $72 \mathrm{hr}$ after surgery after logarithmic transformation - we used $\log _{2}(x+1)$ transformation due to the existence of zeros. We reported the Pearson and Spearman correlation coefficients, as appropriate, and assessed the relationships using a multivariable regression model, adjusting for potential confounders. The TWA of pain scores is equal to the sum of the portion of each time interval in-between two adjacent pain score measurements multiplied by the average of the corresponding two pain scores divided by the time interval between the first and the last pain score measurements. We adjusted for pre-specified potential confounders, including age, sex, body mass index, smoking status, diabetes mellitus, chronic pain syndrome, and chronic usage of steroids and opioids. Nonetheless, chronic pain syndrome and chronic usage of opioids may be potential mediators between vitamin D deficiency and postoperative pain. Adjusting for mediators would "wash out" the associations of interest. Thus, we conducted a sensitivity analysis where we removed these two covariates from the multivariable model.

In addition, we used the same methods as above to conduct a pre-specified secondary analysis comparing 
Table 2 Patient characteristics of the included and excluded bariatric surgical patients in our study

\begin{tabular}{|c|c|c|c|c|c|c|}
\hline \multirow[t]{2}{*}{ Variable } & \multirow{2}{*}{$\begin{array}{l}\text { Included } \\
(n=185)\end{array}$} & \multicolumn{4}{|l|}{ Excluded } & \multirow[t]{2}{*}{ ASD } \\
\hline & & $\begin{array}{l}\text { Missing outcomes or } \\
\text { covariables }(n=25)\end{array}$ & $\begin{array}{l}\text { Vitamin } \mathrm{D}>6 \\
\text { months }(n=82)\end{array}$ & $\begin{array}{l}\text { No vitamin } \mathrm{D} \\
(n=184)\end{array}$ & $\begin{array}{l}\text { Overall } \\
(n=291)\end{array}$ & \\
\hline Age $(y r)$ & $48(12)$ & $49(11)$ & $48(10)$ & $47(11)$ & $47(11)$ & 0.09 \\
\hline Sex(female) & $72 \%$ & $72 \%$ & $76 \%$ & $70 \%$ & $72 \%$ & 0.00 \\
\hline Race & & & & & & 0.35 \\
\hline Caucasian & $81 \%$ & $64 \%$ & $68 \%$ & $78 \%$ & $74 \%$ & \\
\hline African American & $12 \%$ & $36 \%$ & $28 \%$ & $20 \%$ & $23 \%$ & \\
\hline Others & $7 \%$ & $0 \%$ & $4 \%$ & $2 \%$ & $2 \%$ & \\
\hline Body mass index $\left(\mathrm{kg} \cdot \mathrm{m}^{-2}\right)$ & $45(9)$ & $45(9)^{1}$ & $48(8)$ & $47(8)^{6}$ & $47(8)$ & 0.26 \\
\hline Smoking status (smokers) & $48 \%$ & $53 \%^{8}$ & $44 \%^{1}$ & $54 \%^{7}$ & $51 \%^{16}$ & 0.06 \\
\hline Diabetes & $41 \%$ & $52 \%$ & $33 \%$ & $33 \%$ & $34 \%$ & 0.13 \\
\hline Chronic steroid users & $4 \%$ & $0 \%^{10}$ & $1 \%^{1}$ & $3 \%{ }^{11}$ & $3 \%^{22}$ & 0.07 \\
\hline Chronic opioid users & $29 \%$ & $27 \%{ }^{10}$ & $31 \%^{1}$ & $17 \%^{9}$ & $21 \%^{20}$ & 0.18 \\
\hline Chronic pain syndrome & $30 \%$ & $29 \%^{18}$ & $46 \%^{8}$ & $37 \%^{21}$ & $40 \%^{47}$ & 0.20 \\
\hline \multicolumn{7}{|l|}{ During the first $72 \mathrm{hr}$ after surgery } \\
\hline TWA pain scores & $3.8(1.5)$ & $4.1(1.5)^{5}$ & $4.3(1.8)^{2}$ & $4.3(1.7)^{6}$ & $4.3(1.8)^{13}$ & 0.29 \\
\hline $\begin{array}{l}\text { Total opioid consumption (intravenous } \\
\text { morphine equivalent), mg }\end{array}$ & $16[5,33]$ & $20[5,35]$ & $13[0,30]$ & $5[0,25]$ & $10[0,27]$ & 0.30 \\
\hline
\end{tabular}

Statistics are represented as mean (SD), median $\left[1^{\text {st }}, 3^{\text {rd }}\right.$ quartile $]$, or $\%$

Superscripts represent number of missing values

* ASD $=$ absolute standardized difference: the absolute difference in means or proportions divided by the pooled standard deviation; 0.2, 0.5, and 0.8 to represent small, medium, and large standardized differences in absolute values. (Cohen J. Statistical Power Analysis for the Behavioral Sciences (2nd ed.). Hillsdale: Lawrence Erlbaum Associates, Inc., Publishers; 1988.) - TWA = time-weighted average

outcomes of patients with vitamin D deficiency $(\leq 20$ $\left.\mathrm{ng} \cdot \mathrm{mL}^{-1}\right)$ vs patients with a vitamin $\mathrm{D}$ concentration $>20$ $\mathrm{ng} \cdot \mathrm{mL}^{-1}$. A Bonferroni correction was used to adjust for multiple testing; the significance criterion for each outcome was $P<0.025$ (i.e., $0.05 / 2$ ). SAS $^{\circledR}$ software version 9.3 (SAS Institute, Cary, NC, USA) was used for all analyses.

\section{Results}

During July 2005-December 2009, 476 adult patients underwent laparoscopic bariatric surgery at the Cleveland Clinic Main Campus, and 210 patients had a 25-hydroxyvitamin D measurement within three months from the date of surgery. After exclusion for incomplete data, 185 patients were included in the analysis (Table 1). There was a slight imbalance (i.e., ASD > 0.2) between patients who were included in our study and those who were excluded, specifically in terms of demographics, baseline characteristics, and outcomes. For example, patients who were included in the analysis were more likely to be Caucasian (vs African American), to have a lower body mass index and a lower TWA pain score, and to receive more opioids in general; they were also less likely to have chronic pain syndrome (Table 2).
We observed that the mean (SD) of the TWA of pain score was 3.8 (1.5) and the median interquartile range [IQR] of total opioid consumption (intravenous morphine equivalent) was $15.6[18.2] \mathrm{mg}$ during the first postoperative $72 \mathrm{hr}$. The observed median [IQR] of vitamin D concentration was 21.8 [17.1] $\mathrm{ng} \cdot \mathrm{mL}^{-1}$ (Fig. 1).

Vitamin D was not significantly associated with either the TWA of pain score (Pearson correlation: $-0.003 ; 97.5 \% \mathrm{CI}$ : -0.17 to $0.16 ; P=0.97)$ or total opioid consumption (Spearman correlation: $-0.13 ; 97.5 \% \mathrm{CI}$ : -0.30 to 0.03 ; $P=0.07$ ) (Fig. 2). After adjusting for potential confounders, the estimated average change in the TWA of pain score was $0.01(97.5 \% \mathrm{CI}$ : -0.08 to 0.11$)$ for a five-unit increase in vitamin $\mathrm{D}$ concentration $(P=0.77)$. The estimated ratio of geometric means of total opioid consumption was 0.94 (97.5\% CI: 0.86 to 1.03$)$ for a five-unit increase in vitamin D concentration $(P=0.12)$. The sensitivity analysis provided consistent results: the average change in pain score was $0.03(97.5 \% \mathrm{CI}:-0.07$ to $0.13 ; P=0.55)$, and the ratio of geometric means of opioid consumption was 0.94 (97.5\% CI: 0.86 to $1.03 ; P=0.13$ ).

Similarly, no difference was found between patients with vitamin $\mathrm{D}$ concentration $>20 \mathrm{ng} \cdot \mathrm{mL}^{-1}$ vs $\leq 20$ $\mathrm{ng} \cdot \mathrm{mL}^{-1}$, TWA of pain score [mean (SD): 3.7 (1.5) vs 3.9 (1.5), respectively], or total opioid consumption (median 


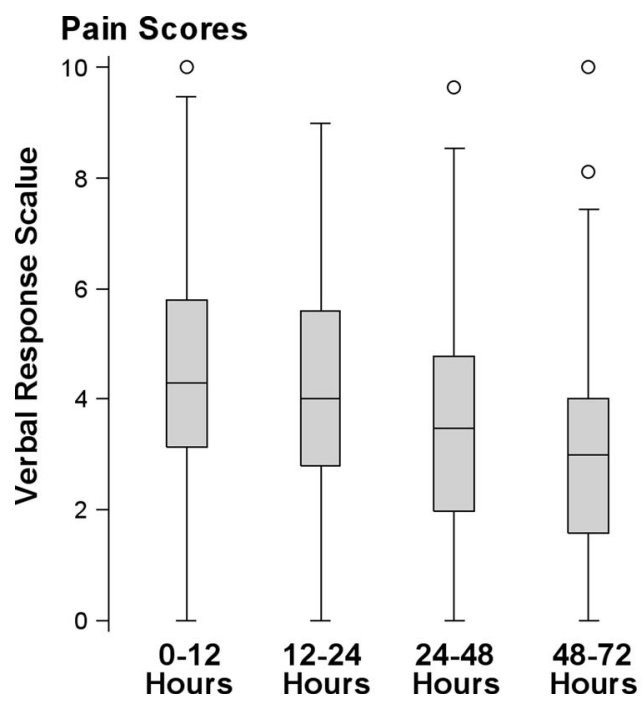

Fig. 1 Boxplots of time-weighted average verbal response pain scores, opioid consumption in $\mathrm{mg}$ (intravenous morphine equivalent dose), and vitamin D concentration for 185 patients included in the analysis. The first quartile, median, and third quartile comprise the

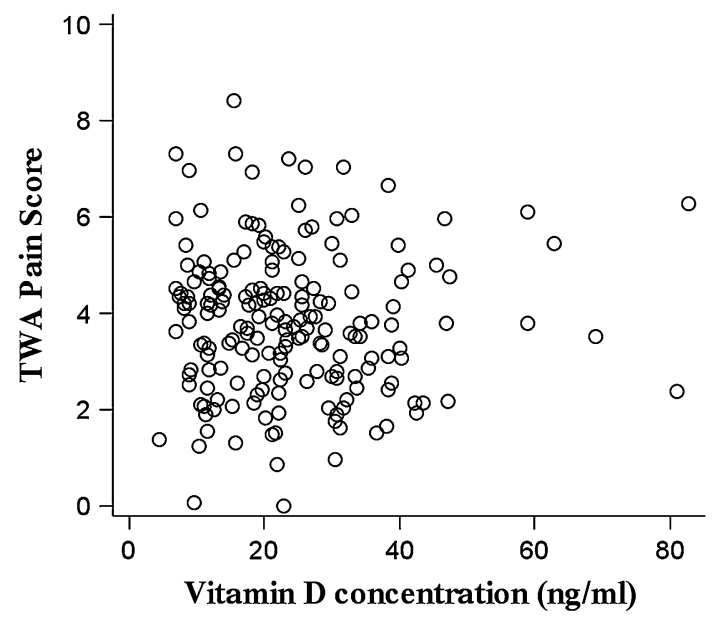

Fig. 2 Scatter plot of vitamin D concentration and the time-weighted average (TWA) of pain score and total opioid consumption during the first postoperative $72 \mathrm{hr}$. Vitamin D was not significantly associated

[Q1, Q3]: 23 [5.0, 30] mg vs 20 [7, 35] mg, respectively); 97.5\% CI 7 to 35 . After adjusting for covariables, the estimated mean difference in pain score was $-0.03(97.5 \%$ CI: -0.56 to $0.51 ; P=0.91)$, while the estimated ratio of geometric means of total opioid consumption was 0.75 (97.5\% CI: 0.46 to 1.22 ) for patients with vitamin D $>20$ vs patients with $\leq 20 \mathrm{ng} \cdot \mathrm{mL}^{-1}(P=0.18)$.

\section{Discussion}

This is a novel study to look at the association between vitamin $\mathrm{D}$ and postoperative pain and opioid consumption. In this study population, we found that vitamin D levels

\section{Opioid Consumption}
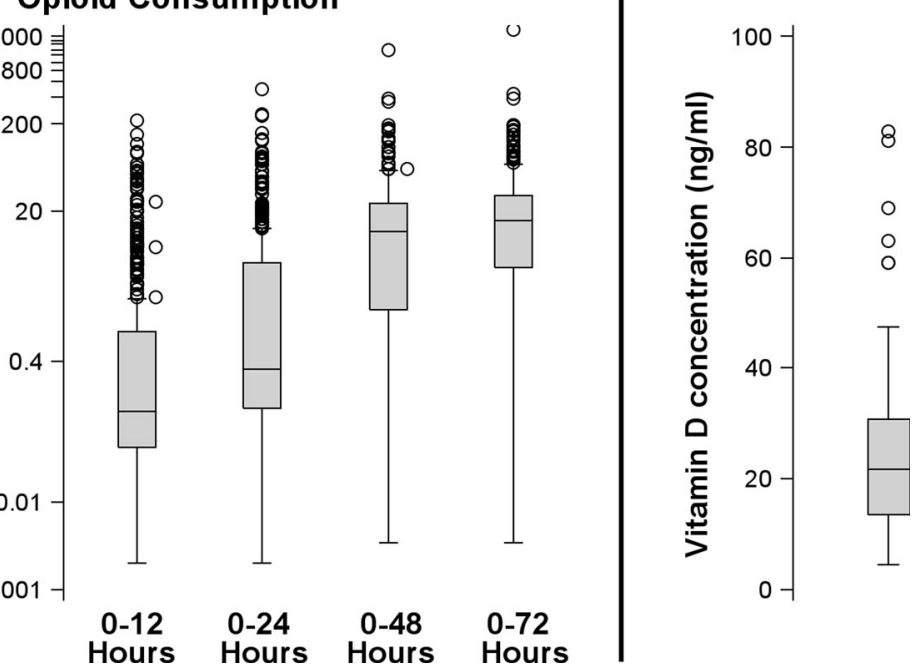

boxes; whiskers extend to the most extreme observations within 1.5 times the interquartile range of the first and third quartiles, respectively; points outsides these whiskers are displayed individually

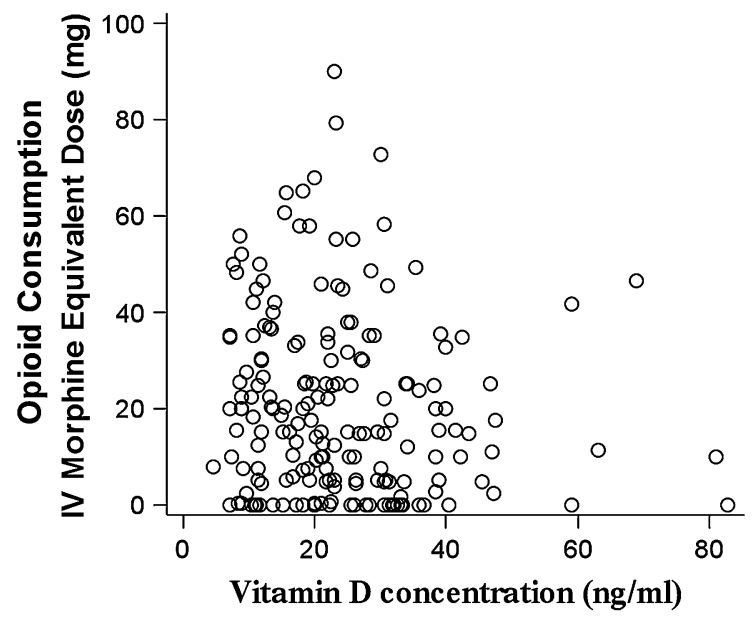

with either the TWA of pain score $(P=0.77)$ or the total opioid consumption $(P=0.12)$, after adjusting for potential confounders

were not associated with pain scores or with opioid consumption in the first $72 \mathrm{hr}$ following surgery. This result is surprising since previous studies have shown that vitamin D deficiency can be associated with the development of chronic nonspecific musculoskeletal pain syndrome, ${ }^{25}$ myalgia, ${ }^{17}$ chronic low back pain, ${ }^{26}$ and chronic tension-type headache. ${ }^{27}$ Some studies even show that supplementation contributes to improvements in pain. ${ }^{28,29}$ Decreased serum vitamin D levels were also associated with diabetic peripheral neuropathy, which is an important reason for chronic pain. ${ }^{30}$

A number of mechanisms have been proposed to explain the role of vitamin D deficiency in chronic pain syndromes. The most important mechanism related to pain is the 
immune-modulatory action of vitamin D shown in in vitro and in vivo studies. Recent studies suggest that vitamin D has anti-inflammatory actions via suppression of the expression of COX-2 (an enzyme involved in the synthesis of prostaglandins) and upregulation of the expression of the enzyme that inactivates prostaglandins. ${ }^{31}$ In addition to proposed immunomodulatory mechanisms, vitamin $\mathrm{D}$ receptors and vitamin D metabolizing enzymes have been found in unmyelinated calcitonin gene-related peptide-positive neurons in the dorsal root ganglia of rats, which suggests that $1,25(\mathrm{OH})_{2} \mathrm{D} 3$ (which is a product of 25-hydroxy vitamin D) might affect those sensory neurons via nuclear or extranuclear signalling pathways. ${ }^{32}$ Tague et al. have shown that laboratory rats on a two- to four-week vitamin $\mathrm{D}$ deficient diet showed skeletal muscle hypersensitivity. The rats' sensory neurons showed enriched vitamin D receptor expression, suggesting that the deficiency state triggers hyperinnervation of skeletal muscle nociceptors and thereby contributes to skeletal muscle pain. ${ }^{33}$ Significant amounts of vitamin D receptors have been revealed in the ventromedial hypothalamus of the human brain, which sends projections to the periaqueductal grey matter and thereby potentially regulates nociceptive signalling through the spinal cord via descending projections of the dorsal horns. ${ }^{34}$ Although a biologic explanation for the role of vitamin $\mathrm{D}$ in states of chronic pain seems plausible, this view was not supported in a recent meta-analysis. ${ }^{35}$ Straube et al. ${ }^{35}$ conducted a meta-analysis of 22 relevant studies in which they reported vitamin D levels and investigated the effects of vitamin D treatment on chronic pain conditions. They could not find convincing evidence of lower vitamin $D$ levels in chronic pain conditions $v s$ control populations or any significant correlation between improvement in pain and vitamin D supplementation. Our findings are in agreement with Straube et $a l .{ }^{35}$ Our study has a few limitations in addition to the ones inherent in retrospective chart reviews. For example, the median vitamin $\mathrm{D}$ level was higher than the accepted cut-off for vitamin D deficiency $\left(<20 \mathrm{ng} \cdot \mathrm{mL}^{-1}\right)$. In addition, these patients were non-consecutively enrolled over a period of five years (2005-2009), and the postoperative pain management regimen was not standardized. The type of surgery we assessed was less painful than open surgical procedures, which may have made the differences in outcome less obvious. Furthermore, any retrospective analysis, including ours, potentially suffers from selection bias. In other words, in the minority $(39 \%, 185 / 476)$ of bariatric surgery patients included in the study, the nature of the relationship between vitamin D and pain scores as well as opioid consumption may not be representative of the relationship within the larger cohort of patients. The extent to which selection bias contributes to our conclusions remains unknown. Nevertheless, the bias is probably not substantial based on the evidence of small ASD values across demographics, baseline characteristics, and the outcomes of patients who were included $v s$ those who were not. The largest ASD value of 0.35 indicates only a small difference. A prospective study could potentially address these limitations by using: a larger sample size, consecutive enrolment, and stratification of vitamin D levels according to race, approximate geographical latitude, season of collection, and type of procedure.

In conclusion, we did not find any association between vitamin D levels, postoperative pain scores and opioid consumption in patients presenting for bariatric surgery. Additional well-designed randomized controlled trials are needed to determine the effect of vitamin $\mathrm{D}$ on postoperative pain scores and opioid consumption.

Funding Departmental sources.

Conflicts of interest None declared.

\section{References}

1. Centers for Disease Control and Prevention. Second National Report on Biochemical Indicators of Diet and Nutrition in the U.S. Population 2012. Atlanta (GA): National Center for Environmental Health; Division of Laboratory Sciences - April 2012. Available from URL: http://www.cdc.gov/nutritionreport/ (accessed January 2015).

2. Holick MF. Vitamin D deficiency. N Engl J Med 2007; 357: 266-81.

3. Carlin AM, Rao DS, Meslemani AM, et al. Prevalence of vitamin D depletion among morbidly obese patients seeking gastric bypass surgery. Surg Obes Relat Dis 2006; 2: 98-103.

4. Wortsman J, Matsuoka LY, Chen TC, Lu Z, Holick MF. Decreased bioavailability of vitamin D in obesity. Am J Clin Nutr 2000; 72: 690-3.

5. Bell NH, Epstein S, Greene A, Shary J, Oexmann MJ, Shaw S. Evidence for alteration of the vitamin D-endocrine system in obese subjects. J Clin Invest 1985; 76: 370-3.

6. Compston JE, Vedi S, Ledger JE, Webb A, Gazet JC, Pilkington $T R$. Vitamin D status and bone histomorphometry in gross obesity. Am J Clin Nutr 1981; 34: 2359-63.

7. Hamoui N, Kim K, Anthone G, Crookes PF. The significance of elevated levels of parathyroid hormone in patients with morbid obesity before and after bariatric surgery. Arch Surg 2003; 138 : 891-7.

8. Johnson JM, Maher JW, DeMaria EJ, Downs RW, Wolfe LG, Kellum JM. The long-term effects of gastric bypass on vitamin D metabolism. Ann Surg 2006; 243: 701-4.

9. Slater GH, Ren CJ, Siegel N, et al. Serum fat-soluble vitamin deficiency and abnormal calcium metabolism after malabsorptive bariatric surgery. J Gastrointest Surg 2004; 8: 48-55.

10. Liu PT, Stenger $S, \mathrm{Li} \mathrm{H}$, et al. Toll-like receptor triggering of a vitamin D-mediated human antimicrobial response. Science 2006; 311: 1770-3.

11. Saggese G, Federico G, Balestri M, Toniolo A. Calcitriol inhibits the PHA-induced production of IL-2 and IFN-gamma and the proliferation of human peripheral blood leukocytes while 
enhancing the surface expression of HLA class II molecules. J Endocrinol Invest 1989; 12: 329-35.

12. Tan $X, L i Y$, Liu $Y$. Paricalcitol attenuates renal interstitial fibrosis in obstructive nephropathy. J Am Soc Nephrol 2006; 17: 3382-93.

13. Noonan $W$, Koch $K$, Nakane $M$, et al. Differential effects of vitamin $\mathrm{D}$ receptor activators on aortic calcification and pulse wave velocity in uraemic rats. Nephrol Dial Transplant 2008; 23: 3824-30.

14. $L i$ YC, Kong J, Wei M, Chen ZF, Liu SQ, Cao LP. 1,25-Dihydroxyvitamin $\mathrm{D}(3)$ is a negative endocrine regulator of the renin-angiotensin system. J Clin Invest 2002; 110: 229-38.

15. Zhang Z, Sun L, Wang $Y$, et al. Renoprotective role of the vitamin $D$ receptor in diabetic nephropathy. Kidney Int 2008; 73: 163-71.

16. Plotnikoff GA. Vitamin D-the steroid hormone prescription for every patient. Minn Med 2003; 86: 43-5.

17. Badsha H, Daher M. Ooi Kong K. Myalgias or non-specific muscle pain in Arab or Indo-Pakistani patients may indicate vitamin D deficiency. Clin Rheumatol 2009; 28: 971-3.

18. Marra A, Leoncini $G$, Mussap M, et al. Severe vitamin D deficiency is associated with frequently observed diseases in medical inpatients. Int J Clin Pract 2014; 68: 647-52.

19. Pearce SH, Cheetham TD. Diagnosis and management of vitamin D deficiency. BMJ 2010; 340: b5664.

20. Straube S, Derry S, Moore RA, McQuay HJ. Vitamin D for the treatment of chronic painful conditions in adults. Cochrane Database Syst Rev 2010; 1: CD007771.

21. Dev R, Del Fabbro E, Schwartz GG, et al. Preliminary report: vitamin $\mathrm{D}$ deficiency in advanced cancer patients with symptoms of fatigue or anorexia. Oncologist 2011; 16: 1637-41.

22. Van Veldhuizen PJ, Taylor SA, Williamson S, Drees BM. Treatment of vitamin D deficiency in patients with metastatic prostate cancer may improve bone pain and muscle strength. J Urol 2000; 163: 187-90.

23. Whitehurst JL, Reid CM. Vitamin D deficiency as a cause of chronic pain in the palliative medicine clinic: two case reports. Palliat Med 2014; 28: 87-9.
24. Cohen J. Statistical Power Analysis for the Behavioral Sciences, 2nd ed. Hillsdale, NJ: Lawrence Erlbaum Associates; 1988.

25. Plotnikoff GA, Quigley JM. Prevalence of severe hypovitaminosis $\mathrm{D}$ in patients with persistent, nonspecific musculoskeletal pain. Mayo Clin Proc 2003; 78: 1463-70.

26. Al Faraj S, Al Mutairi K. Vitamin D deficiency and chronic low back pain in Saudi Arabia. Spine 2003; 28: 177-9.

27. Prakash S, Kumar M, Belani P, Susvirkar A, Ahuja S. Interrelationships between chronic tension-type headache, musculoskeletal pain, and vitamin D deficiency: is osteomalacia responsible for both headache and musculoskeletal pain? Ann Indian Acad Neurol 2013; 16: 650-8.

28. Gloth FM 3rd, Lindsay JM, Zelesnick LB, Greenough WB 3rd. Can vitamin D deficiency produce an unusual pain syndrome? Arch Intern Med 1991; 151: 1662-4.

29. de Torrente la de Jara G, Pecoud A, Favrat B. Musculoskeletal pain in female asylum seekers and hypovitaminosis D3. BMJ 2004; 329: 156-7.

30. Celikbilek A, Gocmen AY, Tanik N, et al. Decreased serum vitamin $D$ levels are associated with diabetic peripheral neuropathy in a rural area of Turkey. Acta Neurol Belg 2014; DOI:10.1007/s13760-014-0304-0.

31. Vojinovic J. Vitamin D receptor agonists' anti-inflammatory properties. Ann N Y Acad Sci 2014; 1317: 47-56.

32. Tague SE, Smith $P G$. Vitamin D receptor and enzyme expression in dorsal root ganglia of adult female rats: modulation by ovarian hormones. J Chem Neuroanatomy 2011; 41: 1-12.

33. Tague SE, Clarke GL, Winter MK, McCarson KE, Wright DE, Smith $P G$. Vitamin D deficiency promotes skeletal muscle hypersensitivity and sensory hyperinnervation. J Neurosci 2011; 31: 13728-38.

34. Eyles DW, Smith $S$, Kinobe $R$, Hewison M, McGrath JJ. Distribution of the vitamin D receptor and 1 alpha-hydroxylase in human brain. J Chem Neuroanat 2005; 29: 21-30.

35. Straube S, Moore AR, Derry S, McQuay HJ. Vitamin D and chronic pain. Pain 2009; 141: 10-3. 